\title{
The Laser Institute of Technology for Education and Research at Camden County College: how it has changed and evolved after 20 years
}

\section{Fred Seeber}

Fred P. Seeber, "The Laser Institute of Technology for Education and Research at Camden County College: how it has changed and evolved after 20 years," Proc. SPIE 9666, 11th Education and Training in Optics and Photonics Conference, 96660J (5 June 2009); doi: 10.1117/12.2208027

SDIE Event: Eleventh International Topical Meeting on Education and Training in Optics and Photonics, 2009, St. Asaph, United Kingdom 


\title{
The Laser Institute of Technology for Education and Research At Camden County College How it has Changed and Evolved after 20 years
}

\author{
Fred P. Seeber \\ Professor of Physics/Photonics \\ Co-PI OP-TEC \\ Camden County College \\ Blackwood, NJ \\ USA
}

\section{ABSTRACT}

The Laser Institute of Technology for Education and Research (LITER), nationally and internationally recognized in the field of Photonics, is a state of the art facility built in 1989 on the campus of Camden County College, Blackwood, NJ. This building consists of six high power laser labs, five low power laser labs and four fiber-optic laboratories. It also contains classrooms and research labs and the facility houses over $\$ 5,000,000$ in equipment. This paper will discuss the evolution of this facility in regards to enrollment in its photonics programs, funding for new equipment purchases and maintaining and updating the facility in laser safety requirements as required by the ANSI Z-136.5 Standard for Educational Institutions. The paper will also discuss how OP-TEC (The National Center for Optics and Photonics Education) has helped to keep this Laser Institute at the cutting edge of photonics education.

The Laser Electro-Optics Technology program at Camden County College, Blackwood, New Jersey was an early pioneer in Laser Technician Education. 
It was founded in 1976 with Dr. Fred P. Seeber as its coordinator. At that time, it was only the fourth such program in the United States. The program started small with limited equipment and space. The classes and labs occupied just a few rooms in one of the college's buildings. After years of success and with the explosive growth of the Photonics industry throughout the 1980's, the faculty saw the need for expansion of the programs and the facilities. In 1984 the college offered the country's first community college program in Fiber Optics. In 1989, with funding from the National Science foundation and New Jersey Higher Education, the Laser Institute of Technology and Educational Research (LITER) broke ground and two year's later the building was open to students and faculty. This facility houses cutting edge equipment in lasers, optics, and telecommunication, including optical time domain reflectometers, optical spectrum analyzers, XFP transreceivers, EZ raman spectrophotometers, farfield beam profilers, and automated interferometers, among others. LITER constantly updates its equipment and inventory through both state and federal grants such as New Jersey workforce grants and National Science Foundation equipment and program grants, along with private grants from industries that support the college's program in photonics. Today Laser Electro-Optics and FiberOptic Technology programs, now Photonics Technology, serve approximately 80 students each year and are premier curricula of their kind in the nation. Graduates of the Laser Electro-Optics curriculum and the Fiber Optics option are in great demand nationwide and receive excellent salaries as a result of their intensive training in these areas. However, student enrollment has fluctuated from a high of 120 students per year to a low of about 60 students per year stabilizing at about 80 students.

The LITER building is a unique facility. Of the more than 1100 community colleges in the United States CCC is the only one having a building that is solely dedicated to Photonics education and research. In New Jersey only Princeton University and Camden County College have such facilities. The building houses 15 laboratories with industry grade equipment, study areas, a traditional classroom, and a large lecture hall/classroom. The building is designed with safety and convenience in mind. The laboratories are separated into three wings: Low-Power Wing, High-Power, and Fiber-Optic Wing. The Low-Power Wing is designed for students in courses like; Intro to Photonics, Optics and Optics Measurements etc. that work with low power lasers and optical equipment. The High-Power Wing is equipped with all types of medical and industrial high-power lasers and is generally intended for second year students with a strong Photonics safety background. 
The Fiber-Optic Wing houses all fiber optic and communications equipment for both first- and second-year courses. Over the past several years the fiber optic wing has received a major upgrade including over 1 million dollars worth of state-of-the-art equipment through the New Jersey High-Tech. Workforce Grant and industry equipment donations. Two new laboratories have been added specializing in optical communication system testing. The Photonics program at Camden County College has two tracts. One being the Laser/Electro Optic Technology option with 6 laser specialty courses, 4 electronics courses, 2 physics courses and 3 math courses. This option is also divided into a non-calculus and calculus path depending on the student's high school curriculum. The second tract is the fiber/optics option with 4 laser specialty courses, 3 fiber/optics courses, 3 electronics courses and with both options 2 computer courses. Again the students in the Fiber/Optics Option can take a calculus path if their background permits. Various certificates in Fiber/Optics can be earned by students currently working in the field. Several on-line hybrid Photonics courses are also offered by Camden County College. The college also has several in-service courses tailored to local industry. The Photonics program at Camden County College is the only full Associate degree program in the State of New Jersey. Since the ATE/NSF OP-TEC Center started Camden County College as a partner institution has developed 2 new on-line hybrid Photonics courses with in person capstone laboratories. These courses not only benefit students at CCC but students throughout the country. This has also contributed to higher enrollment in the program. Several meetings and workshops have been held at CCC to promote the goals of OP-TEC. Various educational materials have been authored by the Photonics faculty at CCC that is now used for training. Below are the Laser Electro-Optic and Fiber-Optic technology options to the Photonics program:

\section{Laser/Electro-Optic Technology}

Degree: Associate in Applied Science

College Code: PHT.AAS

Code

Course

Fi r s t Year/Fi r s t Semester

LFO-101 Introduction to Photonics \& Photonic Safety

MTH-125 College Algebra \& Trigonometry or

MTH-140 Calculus I1

ENG-101 English Composition I

PHY-101 Physics I or
Credits

4

4

3 
PHY-201 Physics III1 4

Humanities Elective 3

18

Second Semester

EET-101 Electrical/Electronic Principles 4

MTH-132 Statistics for Technology or

MTH-150 Calculus II1 4

ENG-102 English Composition II 3

LFO-201 Photonics Materials 3

PHY-102 Physics II or

PHY-202 Physics IV1 4

Second Year/Fi r s t Semester

LFO-211 Photonic-Optic Principles \& Components 4

LFO-212 Pulsed \& CW Lasers 3

LFO-241 Introduction to Fiber Optics 3

EET-211 Electronics I 3

LFO-231 Photonics Measurements 3

HPE..... $\quad$ Health \& Exercise Science Elective 1

Second Semester

LFO-292 Photonics Seminar 1

LFO-221 Photonic \& Electro-Optic Devices 3

LFO-251 Laser Electronics or

EET-212 Electronics II 3

…........ Social Science Elective 3

........... Computer Programming Elective 3

HPE...... Health \& Exercise Science Elective 1

Total Minimum Credits 67

\section{Fiber Optics Technology Option}

\section{Degree: Associate in Applied Science College Code: FBR.AAS}

Code

Course

Credits

Fi r s t Year/Fi r s t Semester

LFO-101 Introduction to Photonics \& Photonic Safety 4

MTH-125 College Algebra \& Trigonometry or

MTH-140 Calculus I1 4

ENG-101 English Composition I 3

PHY-101 Physics I or

PHY-201 Physics III1 
Humanities Elective $\quad 3$

Second Semester

EET-101 Electrical/Electronic Principles 4

MTH-132 Statistics for Technology or

MTH-150 Calculus II1 4

ENG-102 English Composition II 3

LFO-201 Photonics Materials 3

PHY-102 Physics II or

PHY-202 Physics IV1 4

Second Year/Fi r s t Semester

LFO-211 Photonic Optic Principles \& Components 4

LFO-241 Introduction to Fiber Optics 3

LFO-231 Photonic Measurements 3

EET-211 Electronics I 3

........... Social Science Elective 3

HPE..... $\quad$ Health \& Exercise Science Elective 1

Second Semester

LFO-292 Photonics Seminar 1

EET-221 Digital Circuits 3

LFO-294 Fiber Optic Project 3

LFO-242 Advanced Fiber Optics 3

Computer Programming Elective $\quad 3$

HPE...... Health \& Exercise Science Elective 1

Total Minimum Credits 67

As part of the evolution of these Photonics programs Camden County College has partnered with OP-TEC [The National Center for Optics and Photonics Education].

2.OP-TEC: The National Center for Optics and Photonics is funded by the National Science Foundation as a ATE center with the stated mission of promoting photonics education and assisting colleges around the country in developing and implementing educational programs that support expansion of this critical new technology. By providing information materials and networking opportunities colleges and universities around the country can take steps in implementing photonics programs that give their students the opportunity to work in this rapidly expanding, high-demand, high-paying field. Because the number of college degrees in Engineering is decreasing, causing fierce competition for the relatively small pool of qualified optics technicians and engineers the need for many more trained individuals in 
Photonics is apparent. A recent survey of employers showed that the number of U.S. technical jobs in photonics and photonics-enabled technologies is expected to grow more than 1800 per year on average through 2009, an annual increase of more than 6 percent. OP-TEC will also develop new materials in photonics and create career pathways that will begin at the high school level and extend into post secondary degrees. Examples of these technical areas are: Telecommunications, manufacturing, medicine, forensics and homeland security. This consortium of two-year colleges, high schools, universities, national laboratories, industry partners, and professional societies is creating OPTEC. These participating entities have committed to join forces in creating a secondary-to-postsecondary "pipeline" of highly qualified and strongly motivated students and empowering community colleges to meet the urgent need for technicians in optics and photonics. OP-TEC will serve primarily two types of one and two-year postsecondary programs: (1) those devoted to lasers, optics, and photonics technology; and (2) those devoted to technologies that are enabled by optics and photonics. OP-TEC will provide support through curriculum, instructional materials, assessment, faculty development, recruiting, and support for institutional reform. OP-TEC will serve as a national clearinghouse for teaching materials; encourage more schools and colleges to offer programs, courses, and career information; and help high school teachers and community and technical college faculty members develop programs and labs to teach technical content.

The project has four main goals: (1) Serve as a national resource center for optics and photonics education and training. (2) Create, assemble, align, and distribute coordinated curriculum materials designed to support optics, laser, and photonics education in high schools, two-year colleges, and retraining of adult workers. (3) Support established and new photonics education programs in high schools, community and technical colleges, universities, and professional societies. (4) Provide education and training for administrators, counselors, high school teachers, and community college faculty members to prepare them to (a) design new photonics technology programs that meet their local needs; (b) infuse photonics into programs in photonics-enabled technologies; and (c) teach optics, photonics, and lasers using curriculum materials distributed by OP-TEC.

OP-TEC will also establish a national infrastructure for developing and supporting widely disseminated educational programs in cutting-edge, high demand technologies that require photonics. That infrastructure will encompass both the secondary and postsecondary levels and will involve 
collaboration between educators and industry personnel. OP-TEC will help to bridge the gap in the participation of women and minorities in technology and break down geographical socioeconomic barriers, making the study of technology more widely accessible. By providing career pathways in which students begin the pursuit of technical careers early and transition seamlessly into postsecondary programs, OP-TEC will enable students to acquire the skills necessary to compete in the global marketplace. The center's planners project that by the end of year 4 the number of schools using OP-TEC's materials and services will be 150+ colleges and 400+ high schools, representing collectively 700+ high school teachers and postsecondary faculty members. The net result will be a significant increase in the pool of qualified technicians in the many technologies that are enabled by photonics. These following services can and will be provided by OP-TEC:

1. Information about Photonics Technology and Technician Careers

- Provide an overview of optics and photonics technology

- Identify technical areas where photonics is an enabling technology

- Maintain updated needs projections for photonics technicians

- Post job opportunities for photonics technicians

- Maintain a website for information exchange within the photonics community

2. Technical Assistance in Program Feasibility and Planning

- Identify local employers that are involved in the photonics industry

- Determine specific areas of concentration required by local photonics employers

- Assist secondary and postsecondary institutions infusing photonics into existing technical curricula

3. Technical Assistance in Curriculum Design and Development

- Participate in "organizational meetings" of photonics advisory committee

- Adapt the Photonics Skill Standards to meet local/regional needs

- Design and develop career pathways in photonics to meet local industry requirements

- Assist educational institutions in selecting the most effective teaching models

4. Technical Assistance in Designing Laboratories

- Provide guidance in configuring laboratories 
- Recommend equipment and suppliers

- Provide cost estimates

- Assist in selecting laboratory experiments

5. Training

- Provide on-line training for teaching postsecondary optics and photonics principles

- Provide on-line training to understand and implement photonics curricula

- Provide professional development opportunities for high school teachers to enhance their skills in presenting photonics topics

This National Center for Optics and Photonics Education will bring together educational institutions, industry, employers and professional societies working for a common goal to produce for our country qualified individuals in the field of Photonics for now and in the future.

${ }^{1}$.The American National Standard for Safe Use of Lasers in Educational Institutions Z-136.5[2009] applies the requirements of the latest revision of ANSI Z136.1[2007] to the unique environments associated with educational institutions, including teaching laboratories, classrooms, and lecture halls, science fairs as well as projects, and science museums, when they incorporate lasers into their educational process. It is intended for staff and students who use lasers as part of their academic instruction and development in the university, college, secondary, and primary educational environments. The wavelength range of interest includes the ultraviolet, visible, and infrared regions of the electromagnetic spectrum, specifically the wavelength range from $180 \mathrm{~nm}$ to $1 \mathrm{~mm}$. The purpose of the Z-136.5 standard is to provide reasonable and adequate guidance for the safe use of lasers by evaluating and minimizing hazards associated with laser radiation in educational environments. The hazard evaluation procedure used in this standard is based on the classification (Class 1 through Class 4) of the laser or laser system, which is related to the ability of the laser beam to cause biological damage to the eye or skin during intended use. The beam from Class 1 lasers and laser systems are considered to be non-hazardous; Class 4 lasers and laser systems possess the highest potential hazard. Many lasers and laser systems are used in universities, colleges, secondary, and primary schools for teaching, research, laboratory experiments, demonstrations and projects/science fairs. Often large numbers of students work in laboratory 
groups in confined areas, and frequently, different departments share laser systems and installations. It is common to find a variety of lasers of different classes and wavelengths in a single laboratory. Open laser cavities and unrestricted beam paths are also common in these environments. Many of the installations are capable of producing non-beam hazards such as, exposure to chemical, electrical, and optical as well as plasma radiation hazards.

${ }^{3}$.In the typical educational institution utilizing lasers, there is often a changing number of students and faculty involved with various experiments that constantly require new configurations of the laser system and laboratory. Care must be taken to ensure that new traffic patterns and new laser set-ups are installed accordingly with safe laser practices.

4.Environments common to educational settings include:

- Classrooms

- High school and undergraduate teaching laser laboratories

- Graduate teaching laser laboratories

- Science fairs and science projects

- Auditorium demonstrations

- Outdoors

- Entertainment activities

As previously stated one of the main goals of OP-TEC is to serve as a national center for photonics education and training as well as laser Safety. The center will be advising hundreds of high schools and 2YR and 4YR colleges around the country about starting and infusing photonics curricula into the programs of their institutions. Guidance will also be provided for existing programs to maintain a level of excellence. This will take several forms including workshops at a college with an existing laser education program and existing laser laboratories, visits to start up educational institutions desiring to use lasers and the associated optical equipment, online hybrid training courses in photonics with in person laser capstone laboratories. An example of a college where workshops and capstone laboratories were held and will be held at Camden County College, Blackwood, NJ. Again the program at the college which started in 1976 has over 500 graduates who are working as engineers, technicians and managers throughout the photonics industry. Many are presidents and CEOs of their own companies. 
OP-TEC has adopted the ANSI Z-136.5 Laser Safety Standard for Educational Institutions as its guide for advising participating high schools and colleges concerning things as:

1. Laser classification

2. Laser control measures for various grade levels

3. Personal protective equipment

4. Standard operating procedures

5. Nominal Hazard Zones

6. The importance and role of a Laser Safety Officer (LSO)

7. Suggested laser laboratory layouts

and much more. Many people feel that more accidents take place at educational institutions than any other laser application. For this reason OPTEC is making an assertive effort to infuse good laser safety practices using the Z-136.5.

The use of lasers by the academic community continues to dramatically escalate. Academia is inundated with a profusion of lasers, each with a diverse function. Traditional departments such as Biology, Chemistry, and Physics have introduced the use of lasers as an essential element of tutelage. Even the more distinctive departments such as Cancer Research, Civil Engineering, Earth and Planetary Sciences, Plasma Fusion, Spectroscopy, and so forth, have incorporated the laser in the composition of their educational mechanism. The literature indicates most ocular accidents happen during alignment procedures, which is an everyday activity for laser educational laboratories. Also, the improper use of laser safety eye wear is a major area of concern for laser safety in educational institutions. More Class 2 , 3, and 4 lasers are used in universities, colleges, laser electro-optic technical colleges and high schools than probably any other area: for teaching, research laboratory experiments, and demonstrations. Relatively large numbers of students work in laboratory groups in confined areas, with various lasers of different wavelengths in the same laboratory. Open cavity and beam paths of Class 3B and Class 4 lasers are common in these environments. Many educational institutions do not have laser safety officers or standard operating procedures. 
In conclusion, the Laser Electro-Optic Programs at Camden County College in Blackwood, New Jersey started in 1976 with only a HeNe laser and some borrowed equipment from the Physics lab and little more. In the last 33 years the photonics programs and the Liter building (Laser Institute for Education and Research) has become the foremost facility at any two year county college in the northeast and the entire USA. As mentioned previously, the Laser Institute houses over \$5,000,000 in equipment which includes lasers of all wavelengths, cutting edge fiber-optic equipment and all types of measurement instrumentation. Camden County College offers degrees and certificates in various options in photonics. The photonics programs at the college have become a resource for this country and abroad for specialties in Telecommunications and Laser Safety. Constant fine tuning and updating of the Photonics curricula and equipment inventories go on continuously. Enrollment in the programs has fluctuated as changes have taken place in our society and technical fields. The association with OP-TEC has provided new avenues for our students to travel as well as Camden County College becoming a regional center for professional development, especially again in the areas of telecommunications and laser safety. Laser safety is of the utmost importance for any institution using lasers as a tool in their experimentation. PHOTONICS WITH OP-TEC AT CAMDEN COUNTY COLLEGE WILL HAVE A VERY OPTAMISTIC FUTURE

\section{References}

1.ANSI Z-136.5 American National Standard for Safe Use of Lasers in Educational Institutions, Laser Institute of America, Orlando, Florida 2009

2.Seeber, F., (2006) OP-TEC the National Center for Optics and Photonics Education, LIA TODAY, page 1 and 8

3.Seeber, F., (2006) Light Sources and Laser Safety, NSF/ATE Center for Occupational Research and Development, Waco, Texas

4.Seeber, F., Update of national standard for the safe use of lasers in educational institutions, Journal of Laser Applications: Vol. II, No. 5; 1999

Seeber, F., For the Safe Use of Lasers in Educational Institutions. Elementary through University. Education in Optics, Proceedings, SPIE's 40th Annual Meeting, San Diego 1995. 